\title{
Ueber die Spectra der Cometen Winnecke (1877b) und Palisa 1879d).
}

Den Winnecke'schen Cometen $(1877 b)$ habe ich am 7. Mai 1877 mit einem 5 zölligen Fernrohr beobachtet. Der Comet war hell mit gut sichtbarem Schweif und sehr starker Verdichtung der Nebelmasse zu einem deutlichen Kern. Das Spectrum bestand aus den, den Cometenspectren eigenen, drei einseitig (nach blau) verwaschenen hellen Streifen, von denen der mittelste der hellste war. Das continuirliche Spectrum war verhältnissmässig stark.

Den Palisa'schen Cometen $(1879 d)$ beobachtete ich am 13. und 15. September mit dem 11/2 zölligen Schröder'sehen Fernrohre des Potsdamer Observatoriums. Der Comet erschien fast rund, bei schwacher Vergrösserung war eine kurze, schweifartige Verlängerung sicht- bar- Der Comet machte den Eindruck eines Stern haufens, der an der Grenze der Auflöslichkeit steht, er war in der Mitte verdichtet, doch ohne eigentlichen Kern. Das Spectrum bestand wieder aus drei einseitig verwaschenen Streifen. von denen der brechbarste (vielleicht nur in Folge des tiefen Standes des Cometen und der in geringen Höhen stärker wirkenden Absorption unserer Atmosphäre auf blaue Strahlen) recht schwach war. Ich. schätzte die Intensität der Streifen, von Roth nach Blau gehend, zu bezw. 6, 10, 3. Das continuirliche Spectrum war schwach.

Potsdam, Dec. 2, 1879.

Prof. Dr. H. C. Vogel.

\section{Occultazioni di $\alpha$ Scorpii e $\delta$ Geminorum}

osservate nella $R$. Specola di Padova.
I879 Luglio 28.
medio di Padova
$\begin{aligned} \text { Riapparizione } & \text { Os servatori } \\ I^{\mathrm{h}} 27^{\mathrm{m}} 43^{\mathrm{h}} 3 & \text { Lorenzoni } \\ 42.7 & \text { Abetti } \\ 43.3 & \text { Zona. }\end{aligned}$

I 879 Novembre 4.

Tempo medio di Padova $\left\{\begin{array}{ccc}\text { Sparizione } & \text { Riapparizione } & \text { Osservatori } \\ \mathrm{II}^{\mathrm{h}} 33^{\mathrm{m}} 7^{\mathrm{s}} 2 & 12^{\mathrm{h}} 39^{\mathrm{m}} \mathrm{I}^{\mathrm{s}} 2 & \text { Lorenzoni } \\ 9.4 & \mathrm{I} 2.2 & \text { Zona } \\ 7.8 & \mathrm{I} 3 \mathrm{I} & \text { G. Naccari. }\end{array}\right.$

Su queste osservazioni e coi dati del Nautical Almanac di Londra il prof. Zona ha formato le equazioni seguenti :

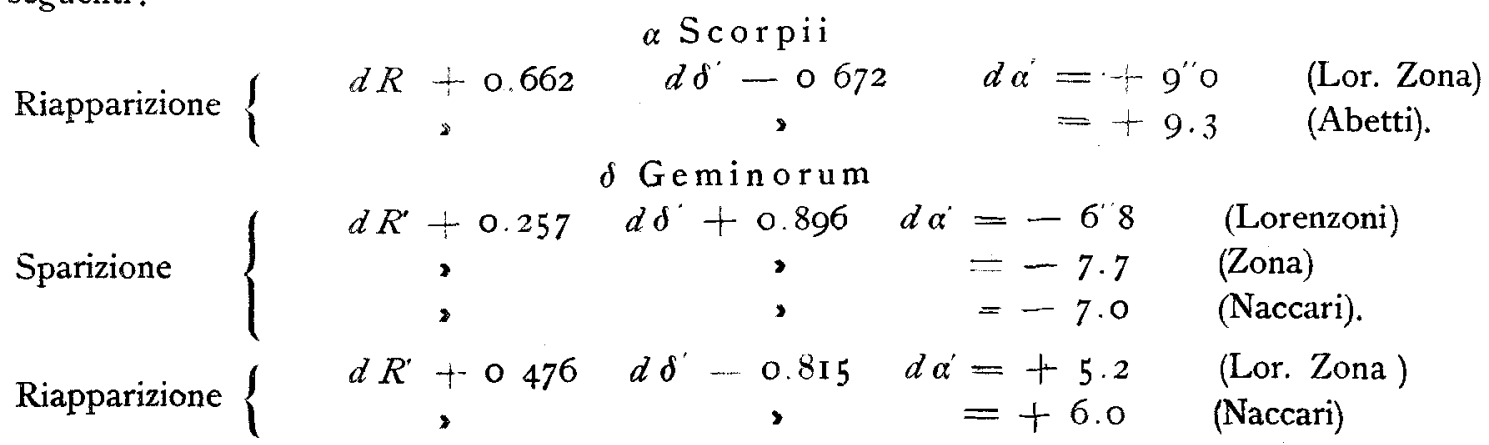

nelle quali $d \alpha^{\prime}, d \delta^{\prime}, d R^{\prime}$ indicano le correzioni incognite della ascensione retta, della declinazione e del semi diametro lunare. - 